\title{
A visita domiciliar de enfermeiros e agentes comunitários de saúde da Estratégia Saúde da Família
}

\author{
Home visits by Family Health Strategy nurses and community health agents
}

La visita domiciliaria de enfermeros y agentes comunitarios de salud de la Estrategia Salud de la Familia

Luciana Valadão Alves Kebian ${ }^{1}$, Sonia Acioli ${ }^{2}$

1 Enfermeira, Mestre em Enfermagem. Rio de Janeiro, Rio de Janeiro, Brasil. E-mail: lucianavvalves@hotmail.com.
2 Enfermeira, Doutora em Saúde Coletiva. Professora Adjunta da Faculdade de Enfermagem da UERJ. Professora do Programa de Pós-Graduação em
Enfermagem da Universidade do Estado do Rio de Janeiro. Rio de Janeiro, Rio de Janeiro, Brasil. E-mail: soacioli@gmail.com.

\section{RESUMO}

Este artigo teve como objetivo descrever as práticas desenvolvidas por enfermeiros e agentes comunitários de saúde no contexto da visita domiciliar da Estratégia Saúde da Família. É um estudo descritivo de abordagem qualitativa. A coleta de dados, realizada entre janeiro e março de 2010, utilizou entrevistas semi-estruturadas com oito enfermeiros e sete agentes comunitários de saúde de duas unidades de saúde da família do município do Rio de Janeiro. Os dados foram submetidos à análise de conteúdo. Observou-se interação baixa entre enfermeiro e agente comunitário de saúde na visita domiciliar. A sobrecarga de trabalho e a violência estão entre as principais dificuldades identificadas para a realização da visita domiciliar. Evidenciou-se um planejamento da visita domiciliar assistemático. Recomenda-se intensificar os momentos de educação permanente, a fim de discutir de modo problematizador os papeis e as atribuições de cada membro da equipe na visita domiciliar, assim como a sistematização desta atividade.

Descritores: Saúde da Família; Enfermagem; Agente Comunitário de Saúde; Visita Domiciliar.

\section{ABSTRACT}

The objective of this article was to describe the practice of nurses and community health agents within the context of the Family Health Strategy home visits. This is a descriptive study with a qualitative approach. Data collection was performed between January and March of 2010, through semi-structured interviews with eight nurses and seven community health agents from two family health units in the city of Rio de Janeiro. Data were submitted to content analysis. Low interaction was observed between nurses and community health agents in the home visits. Work overload and violence are the main hindrances identified for performing home visits. It was found that the home visit planning was unsystematic. Permanent education should be intensified with the purpose to discuss, following a problem-posing approach, the roles and attributions of each team member in the home visit, as well as the systematization of this activity.

Descriptors: Family Health; Nursing; Community Health Workers; Home Visit.

\section{RESUMEN}

Se objetivó describir las prácticas desarrolladas por enfermeros y agentes comunitarios de salud en el contexto de visitas domiciliarias de la Estrategia Salud de la Familia. Estudio descriptivo, de abordaje cualitativo. Datos recolectados entre febrero y marzo de 2012, aplicándose entrevistas semiestructuradas a ocho enfermeros y siete agentes comunitarios de salud de dos unidades de salud de la familia del municipio de Rio de Janeiro. Los datos fueron sometidos a análisis de contenido. Se observó baja interacción entre enfermeros y agentes comunitarios de salud en las visitas domiciliarias. La sobrecarga laboral y la violencia se ubican entre las principales dificultades identificadas para la realización de visitas domiciliarias. Se evidenció planificación asistemática de la visita domiciliaria. Se recomienda intensificar los procesos de capacitación permanente, a fin de discutir de manera problematizadora los papeles y atribuciones de cada miembro del equipo en la visita domiciliaria, así como la sistematización de esta actividad.

Descriptores: Salud de la Familia; Enfermería; Agentes Comunitarios de Salud; Visita Domiciliaria. 


\section{INTRODUÇÃO}

A Estratégia Saúde da Família (ESF) tem como principal finalidade a reorganização da atenção básica no país. É considerada uma estratégia de expansão e qualificação da atenção básica por fortalecer a premissa de levar a saúde para perto das famílias e ser a porta de entrada nos serviços. Atua com equipes multidisciplinares, compostas no mínimo por um médico generalista ou de família, um enfermeiro, um técnico de enfermagem e quatro a seis agentes comunitários de saúde (ACS $)^{(1)}$.

A ESF possui como princípios de reorganização da atenção básica a adscrição da clientela, a qual se refere ao vínculo permanente estabelecido entre a população e as equipes de saúde; a territorialização, que implica na relação precisa entre território e população; o diagnóstico da situação de saúde da população, realizado a partir da análise da situação de saúde do território, mediante cadastramento das famílias e dos indivíduos; e o planejamento baseado na realidade local, que permite a organização de ações de saúde coerentes com as necessidades da população(2).

A ESF prevê a cobertura populacional através de áreas geográficas, a qual deve considerar a diversidade sociopolítica, econômica, densidade populacional, acessibilidade aos serviços, entre outros fatores na delimitação das áreas, definindo, assim, o território de atuação. Dentre as atividades realizadas pela equipe de saúde da família, a visita domiciliar destaca-se por ser desenvolvida no território de atuação, mais especificamente no domicílio do usuário.

A visita domiciliar na ESF é um instrumento utilizado pelas equipes para inserção e conhecimento do contexto de vida da população, assim como estabelecimento de vínculos entre profissionais e usuários. Ainda, visa atender as diferentes necessidades de saúde, preocupando-se com a infraestrutura (habitação, higiene, saneamento entre outros) existente nas comunidades e o atendimento à saúde das famílias ${ }^{(3)}$.

Sendo assim, a visita domiciliar é uma das principais atividades que permite aos enfermeiros e ACS conhecerem o contexto social e identificarem as necessidades de saúde das famílias assistidas pela equipe, permitindo uma maior aproximação com os determinantes do processo saúde-doença.

No entanto, estudos recentes evidenciam problemáticas inerentes à prática da visita domiciliar, como a mudança de famílias, endereços errados e até mesmo recusas. Problemas atrelados à relação família e profissional de saúde também são citados, pois a visita domiciliar adentra a intimidade do lar, o que pode gerar desconforto às famílias ${ }^{(4-5)}$. Além disso, na visita domiciliar podem ser identificadas situações complexas, como violência familiar, miséria e consumo de drogas, que exigem atuação interdisciplinar, intersetorial e participação do usuário, mas que acabam se tornando angústias devido aos entraves para se traçar esse tipo de trabalho na $\mathrm{ESF}^{(6)}$.

Devido as problemáticas identificadas e as expectativas de mudança assistencial, criadas em torno da assistência domiciliar, como a redução das práticas hospitalocêntricas e estratificadas, essa atividade tem sido identificada como uma das mais delicadas e complexas da proposta saúde da família. Com isso, a visita domiciliar representa um grande desafio aos profissionais de saúde, no que tange a integralidade da assistência e a satisfação de usuários e gestores de saúde ${ }^{(7)}$.

Além do exposto, a aproximação com enfermeiros e ACS no cotidiano profissional e acadêmico revelam que esses dilemas estão intensamente presentes nas visitas domiciliares realizadas por esses profissionais. Com isso, sentiu-se a necessidade de investigar como as práticas de saúde estão sendo desenvolvidas por enfermeiros e ACS na visita domiciliar.

o objetivo deste artigo é descrever as práticas desenvolvidas por enfermeiros e agentes comunitários de saúde no contexto da visita domiciliar da Estratégia Saúde da Família.

\section{METODOLOGIA}

Este é um estudo descritivo de abordagem qualitativa, que utilizou como técnica de coleta de dados entrevistas semiestruturadas. As entrevistas foram gravadas e posteriormente transcritas e digitadas em Word. O roteiro de entrevista foi constituído de duas partes: na primeira constavam os dados de identificação do entrevistado, como idade, tempo de profissão, tempo de atuação na ESF entre outros; na segunda parte constavam as perguntas semiestruturadas, as quais visavam responder aos objetivos desta pesquisa. A coleta de dados foi realizada no período de janeiro a março de 2010.

O cenário do estudo foi duas Unidades Básicas de Saúde da Família (UBSF) do município do Rio de Janeiro. A Atenção Básica à Saúde na cidade do Rio de Janeiro está distribuída em áreas de planejamento (AP). Neste estudo, o critério de inclusão da AP e das UBSF foi o maior quantitativo de equipes de saúde da família. A AP incluída possuía 49 equipes e as duas UBSF com maior número de equipes desta AP eram compostas por cinco e sete equipes cada. 
Uma das UBSF está localizada em um conjunto de comunidades que abriga uma população estimada em 69.000 pessoas. A região é marcada pela pobreza, violência e exclusão social, além do alto índice de desemprego e baixa escolaridade ${ }^{(8)}$.

A outra UBSF fica localizada em uma comunidade com cerca de 4.000 domicílios e uma população estimada de quase 12.000 pessoas. Entretanto, faz parte de um conjunto de comunidades que possui aproximadamente 130.000 moradores, a qual apresenta uma alarmante situação de pobreza e violência( ${ }^{(8)}$.

Os sujeitos deste estudo foram enfermeiros e ACS. Os critérios de inclusão foram, concordar com a participação no estudo e atuar há mais de seis meses na AP. Com isso, nesta pesquisa participaram 15 sujeitos, oito enfermeiros e sete ACS. Para a realização da coleta de dados, foi feito um contato prévio com os enfermeiros e ACS com o objetivo de verificar o melhor horário e local para a apresentação da pesquisa e aplicação das entrevistas (todas as entrevistas foram realizadas na UBSF).

A técnica de análise de dados utilizada nesta pesquisa foi a de conteúdo(9), com ênfase na análise de conteúdo temático-categorial. As etapas utilizadas para tratamento dos dados foram: pré-análise - realizou-se a leitura flutuante dos depoimentos, que se constituiu no corpus da análise, seguido pela leitura exaustiva do material; análise - selecionou-se as unidades de registro (frases) formando um recorte dos relatos e posterior organização. A seguir, foi organizada a grade de eixos temáticos da qual surgiram as seguintes categorias: práticas de saúde do enfermeiro e ACS na ESF; visita domiciliar do enfermeiro e ACS na ESF; e sentidos atribuídos pelos enfermeiros e ACS acerca das práticas de saúde desenvolvidas na visita domiciliar.

Este artigo apresenta os resultados da categoria "visita domiciliar do enfermeiro e ACS na ESF", a qual se desdobra em três subcategorias: a interação entre enfermeiro e ACS na visita domiciliar, identificando as dificuldades para a realização da visita domiciliar e o planejamento da visita domiciliar.

Os profissionais participantes deste estudo expressaram sua concordância através da assinatura do Termo de Consentimento Livre e Esclarecido(10). Para preservar o anonimato, os participantes foram identificados com a letra "E" (Enfermeiro) e "A" (ACS), seguido de um número de identificação. A pesquisa foi aprovada através do parecer no 324A/09 do Comitê de Ética em Pesquisa da Secretaria Municipal de Saúde e Defesa Civil do Rio de Janeiro.
Quanto a limitação do estudo aponta-se a restrição do campo de estudo em duas UBSF da cidade do Rio de janeiro e amostra de sujeitos inferior a planejada. No entanto, tais limitações justificam-se pelo curto período para realização da pesquisa e a dificuldade de contato com os profissionais da ESF, que restringiram a inserção de mais sujeitos na pesquisa.

\section{RESULTADOS E DISCUSSÃO}

A partir dos dados desta pesquisa foi possível descrever e refletir sobre a prática de enfermeiros e de ACS na visita domiciliar. Os aspectos mais relevantes foram: a interação de enfermeiros e ACS, as dificuldades, e o planejamento na visita domiciliar.

Dos ACS entrevistados seis eram do sexo feminino e um era do sexo masculino. Já a categoria de enfermagem foi composta somente pelo sexo feminino. A média de idade entre os enfermeiros foi de 36,3 anos e entre os ACS foi de 34 anos. Quanto ao tempo de profissão identificouse a média de 8,17 anos para os enfermeiros e 7,32 anos para os ACS. Referente ao tempo de atuação na ESF identificou-se a média de 3,77 anos para os enfermeiros e 6,03 anos para os ACS.

\section{A interação entre enfermeiro e ACS na visita domiciliar}

Identificou-se que em algumas equipes há pouca interação entre os profissionais, dificultando a comunicação e a sintonia entre eles. São preocupantes os resultados que podem surgir desta baixa interação na visita domiciliar, uma vez que a dinâmica desta atividade se dá através da identificação das necessidades dos usuários pelo ACS e posterior repasse aos demais profissionais de saúde, sendo o diálogo e a harmonia fundamentais neste momento.

Falta um pouquinho de interação, não só aqui, acredito que na maioria das UBSF o agente [ACS] tenha que saber interagir um pouquinho mais, tem que estar mais participativo dentro da equipe. (E1)

Se você consegue interagir com todos os profissionais isso facilita muito o trabalho dentro da unidade. (E1)

A pouca interação entre os profissionais pode ser resultante de relações interpessoais frágeis ou da dificuldade em superar a fragmentação do trabalho e construir uma prática interdisciplinar. Embora a ESF preveja a articulação entre os diferentes saberes e práticas dos profissionais da equipe de saúde, as pesquisas têm demonstrado distanciamento entre eles, 
tanto nas atividades realizadas na UBSF quanto nas atividades externas e na visita domiciliar(11-12).

Trabalhar de maneira integrada na ESF significa estabelecer conexões entre os distintos processos de trabalho, fundamentando-se em certo conhecimento sobre o trabalho do outro e na valorização das contribuições deste na produção do cuidado(13). Nesse sentido, uma prática que facilita a interação entre os profissionais é a reunião de equipe, que deve ocorrer semanalmente com o objetivo de discutir e organizar as demandas da comunidade e as situações inerentes ao processo de trabalho. Esta é uma ferramenta que possibilita reflexões sobre a prática, troca de experiências e planejamento das ações, ou seja, é um momento que propicia a integração da equipe de saúde da família.

Quando questionados sobre a interação entre o enfermeiro e o ACS na visita domiciliar, os enfermeiros demonstraram preocupação em orientar o ACS de modo a possuir uma coerência no momento da visita domiciliar para ambos seguirem as mesmas orientações e condutas.

A minha enfermeira se sente segura para que eu fale tudo.

É fundamental o enfermeiro confiar na atuação do ACS. Do contrário, a interação entre estes profissionais fica fragilizada, acarretando em práticas de saúde divergentes. A ausência de confiança e parceria pode induzir a momentos de conflito entre o enfermeiro e o ACS durante a visita domiciliar.

Também observou-se nos relatos que a presença constante do ACS na comunidade faz com que este domine informações que os demais profissionais desconhecem, o que caracteriza seu saber como empírico. Sendo assim, no momento em que o enfermeiro e o ACS realizam a visita domiciliar juntos, estas informações tornam-se relevantes para o desenvolvimento das práticas de saúde, pois complementam o saber científico do enfermeiro.

Eu posso dar informações que às vezes só eu tenho e que ela [enfermeira] não sabe. Eu posso estar ajudando ela assim. (A5)

O saber empírico que o ACS possui da comunidade faz com que suas orientações sejam coerentes com a realidade da população, favorecendo o entendimento e a

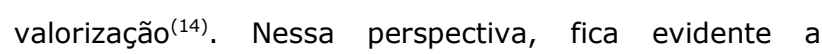
importância da interação do enfermeiro e do ACS na visita domiciliar, pois seus saberes se complementam em prol de uma ação coerente e resolutiva.

Os resultados mostram que o ACS é o primeiro profissional da equipe a identificar o problema. Habitualmente, quando a situação requer uma atenção especializada ele recorre ao técnico de enfermagem ou ao enfermeiro, como, por exemplo, na necessidade de realizar um curativo ou orientar sobre um tratamento no domicílio. Do mesmo modo, quando necessário, o enfermeiro solicita a presença do médico no domicílio para dar continuidade ao atendimento, por exemplo, para definir um diagnóstico ou prescrever um medicamento. Estudo realizado no Estado de São Paulo corrobora com o achado ao colocar que os ACS são solicitados pela equipe para contribuírem na elaboração do plano de cuidados da família, assim como eles também procuram pelos outros trabalhadores quando se deparam com necessidades da população que não conseguem solucionar sozinhos(12).

Os relatos evidenciam a percepção de que o enfermeiro e o ACS são os responsáveis por identificar o problema de saúde na visita domiciliar, enquanto o médico é o responsável em solucionar este problema. Esta percepção remete ao modelo médico-assistencial privatista, no qual a assistência à saúde é centrada no saber biomédico. Neste modelo o diagnóstico e a prescrição médica são valorizados em detrimento da promoção da saúde e prevenção de doenças, tornando o profissional médico agente principal da assistência à saúde(15).

Levo a enfermeira lá para realmente detectar aquele problema, ela passa pro médico, o médico resolve, entendeu? (A2)

Entretanto, sabe-se que a ESF reflete uma proposta de mudança no modelo de atenção à saúde, o qual defende uma assistência à saúde integral, ou seja, que abranja desde a promoção da saúde até a reabilitação dos agravos da população(15). Nesse sentido, a valorização da assistência à saúde curativa, não condiz com os objetivos da ESF. Além disso, a ESF prevê que a assistência à saúde seja planejada em equipe, fazendo com que cada profissional contribua com suas atribuições específicas e desfragmente o foco médico-curativo.

\section{Identificando as dificuldades para a realização da visita domiciliar}

Entre os enfermeiros a dificuldade mais evidenciada foi a sobrecarga de tarefas na UBSF que consomem grande parte do tempo e, consequentemente, interferem 
na realização da visita domiciliar. A insatisfação dos enfermeiros em relação a sobrecarga de trabalho fica evidente nos relatos, principalmente ao referirem que são designados para realizarem atividades e resolverem problemas que também são de competência dos demais profissionais.

Não estou dizendo que eu não tenha que ir na visita. Mas quem é que ia resolver o problema da coleta de preventivo, das crianças menores de um ano, gestante sem pré-natal, sem primeira consulta de orientação, mas se eu não fizer isso não dá conta. [...] Você vai ver que quando uma enfermeira não está fazendo a visita é devido a porta de demanda, pela demanda que acontece não realizo a visita domiciliar. (E5)

A enfermeira tem que ser assistente social, tem que ser mãe, pai [...]. Mas por você gostar acaba assumindo e no final não entende porque está estressada. É esse excesso de procura, que não chega para o médico ou para o dentista atender, é o enfermeiro, enfermeiro, enfermeiro. (E8)

O acúmulo excessivo de atividades, tanto específicos do enfermeiro quanto referentes à equipe de saúde, é um dilema recorrente na enfermagem. Na ESF, as exigências de produtividade e o cadastramento ultrapassado subestimando o número de famílias da área colaboraram para a sobrecarga de trabalho(11). Devido ao número elevado de atividades e o tempo limitado, muitos enfermeiros optam por realizar as atividades da UBSF, como as consultas de enfermagem, em detrimento das visitas domiciliares. Tal achado também foi evidenciado em outros estudos, que destacam a falta de tempo e o excesso de atividades como limitador para o enfermeiro realizar a visita domiciliar ${ }^{(11,16)}$.

A sobrecarga de trabalho também afeta o ACS. Ele argumenta atuar em diversas funções, entretanto se avalia que ele receba uma grande demanda de trabalho por que suas atribuições são muito amplas e nem sempre consideram as singularidades de cada região e da população(17). A falta de clareza sobre quais são as atribuições dos ACS pode provocar sobrecarga de funções e até de papéis, ocasionando uma responsabilização excessiva em torno deste profissional(17-18). Consequentemente, a sobrecarga de trabalho dificulta que o ACS dedique seu tempo e atenção à realização da visita domiciliar.

Os enfermeiros também relataram dificuldade com a carência de equipamentos portáteis, como aparelhos de hemoglucoteste (HGT) e balanças. Nestas situações, problemas simples que poderiam ser resolvidos no domicílio são encaminhados à UBSF, ocasionando uma demanda ainda maior no local. Problemática semelhante foi identificada em uma pesquisa, na qual $86,8 \%$ dos profissionais referem-se como dificuldade do cotidiano de trabalho da ESF a indisponibilidade de equipamentos e instrumentos ${ }^{(19)}$.

O desconhecimento e o medo de caminhar na área da comunidade também foram dificuldades citadas pelos enfermeiros. Neste momento, o ACS acompanha o profissional até o domicílio, uma vez que ele possui o conhecimento sobre sua microárea, minimizando, assim, a dificuldade encontrada pelos enfermeiros.

Eu não sei andar aqui dentro direito, porque eu era de outra UBSF, eu tenho medo. Tenho medo mesmo, porque tem rua que eu não conheço. (E2)

O ACS convive com situações semelhantes as dos usuários do serviço, o que o possibilita criar uma relação de aproximação com os moradores e compreender a realidade local. O ACS por ser morador local e ter uma relação diferenciada com a comunidade é usado como recurso de proteção contra a violência pelos demais profissionais da ESF; sendo geralmente companhia da equipe nas visitas domiciliares ${ }^{(20)}$. No entanto, é importante destacar que o ACS vivencia a mesma violência como morador e como trabalhador, o que intensifica o sofrimento e o risco gerado pela exposição.

Identifica-se nos enfermeiros características de um trabalho dominado pelo medo, justamente em uma estratégia que prevê a atuação pelo estabelecimento de vínculos e comprometimentos com a comunidade ${ }^{(21)}$. Este paradoxo no trabalho dos profissionais da ESF pode prejudicar o processo de trabalho, pois os profissionais tem medo de ir a campo.

Entre os ACS foi citado como dificuldade de realização da visita domiciliar a grande demanda da população pelos seus serviços. Eles relataram que ao irem realizar a visita domiciliar agendada, são abordados no caminho por outros moradores, retardando sua chegada ao domicílio de destino e, consequentemente, originando adiamento de algumas visitas domiciliares para o próximo dia.

Por vezes o ACS necessita comparecer mais de uma vez ao mês na mesma família, o que acaba dificultando a realização da visita domiciliar em todas as famílias. Como ele possui um grande número de famílias em sua microárea, situações como a relatada fazem com que o ACS opte por comparecer mensalmente nas famílias que 
possuem alguma prioridade de saúde e não tão frequentemente nas demais famílias.

Quando você visita várias vezes uma mesma família que tem um problema crônico você termina deixando uma família que não tem problema nenhum sem visitar. (A1)

Dificuldade semelhante foi abordada em estudo realizado na cidade de São Paulo, o qual refere que os ACS nem sempre conseguem visitar todas as famílias cadastradas em um mês. Isso acontece, porque o ACS está também inserido em outras atividades além das visitas e porque o tempo dedicado às visitas é reduzido ${ }^{(16)}$.

Nesta situação, fica visível o conflito existente entre o trabalho prescrito e o trabalho real. Dentre as atribuições do ACS está o acompanhamento de todas as famílias de sua microárea através da visita domiciliar (trabalho prescrito), porém os entraves do cotidiano o impedem de realizar esta atividade fidedignamente, pois ele prioriza algumas famílias (trabalho real).

O distanciamento entre o trabalho prescrito e o trabalho real pode ser gerador de sofrimento ao trabalhador, uma vez que aproximar as atribuições profissionais das atividades cotidianas é difícil em alguns contextos. Entretanto, é preciso entender que "trabalhar é preencher a lacuna entre o prescrito e o real" e por isso, a busca pela aproximação destas duas dimensões deve ser entendida e aceita como um (re)inventar cotidiano(22).

Enfermeiros e ACS fazem referência a outro obstáculo na realização da visita domiciliar, a violência. Muitas UBSF estão localizadas em áreas pobres das cidades, territórios em geral dominados violentamente por grupos armados em constante conflito entre eles e com a polícia, que afetam de modo intenso a rotina dos moradores e dos profissionais de saúde que ali atuam.

Infelizmente acho que pela área ser de risco acaba te limitando muito, porque você deixa de fazer muita visita domiciliar se a rua está agitada, algum problema com eles a nível de comando, ai pede para o pessoal não ir para a rua. Eu acho que aquilo ali já é um dia que você perdeu, que você é obrigada a ficar dentro do posto, eu acho que o chato é isso. (E2)

Na ESF o convívio com a violência fica ainda mais acentuado devido ao contato estreito entre os profissionais e a população atendida, como atendimentos em ambientes abertos e visitas domiciliares. Tais fatores aumentam a vulnerabilidade do trabalhador da ESF, podendo acarretar agravos em sua saúde(23) e interferências no processo de trabalho.

A dificuldade de acesso a certos pontos da comunidade foi destacada por enfermeiros e ACS. Eles relatam que alguns locais são altos e/ou não possuem calçamento, dificultando o acesso dos profissionais principalmente em dias chuvosos. Às vezes, é necessário esperar alguns dias para ter acesso novamente à área, ocasionando dias de trabalho sem realizar a visita domiciliar.

Os relatos demostram que o principal limitador dos enfermeiros e agentes comunitários de saúde, para a realização das visitas domiciliares, é a sobrecarga de trabalho na UBSF. Entretanto, considera-se que o desconhecimento e o medo de caminhar na área da comunidade, a violência e dificuldade de acesso a certos pontos da comunidade, são aspectos que podem tanto dificultar quanto impedir a realização da visita domiciliar, contribuindo para o desenvolvimento de práticas dentro da unidade.

\section{O planejamento da visita domiciliar}

A visita domiciliar deve ser realizada de forma sistematizada pelas equipes de saúde da família. Para isso, são traçadas formas de planejar, executar, registrar e avaliar a ação(24). Neste estudo, será abordado o primeiro item, ou seja, o modo como os enfermeiros e ACS realizam o planejamento da visita domiciliar.

Sabe-se que o ACS deve realizar pelo menos uma visita domiciliar mensal às famílias de sua microárea(1), porém identificou-se nos relatos que quando isso se torna impossível ele prioriza a visita domiciliar para alguns usuários. Além disso, evidenciou-se que o enfermeiro realiza a visita domiciliar aos usuários que requerem maior atenção, seguindo prioridades de atendimento estabelecidas tanto pelo Ministério da Saúde ${ }^{(1)}$ quanto da própria equipe.

Os relatos mostram que de modo geral as prioridades são dadas aos usuários acamados ou que tenham dificuldade de se locomover até à UBSF, hipertensos, diabéticos, soropositivos, gestantes, crianças menores de dois anos ou desnutridas, idosos, pessoas com hanseníase ou tuberculose, e pessoas em pós-operatório. Este achado vai ao encontro dos critérios de prioridade embasados nos indicadores de saúde da população brasileira, que ainda possui índices de mortalidade elevados para esses grupos $^{(24)}$. A ausência de visita domiciliar mensal em todas as famílias pode fazer com que não sejam identificadas necessidades importantes, representando uma problemática para a atenção à saúde dessas pessoas. No 
entanto, percebe-se um esforço por parte dos enfermeiros e ACS em visitar os grupos prioritários, na busca por zelar a saúde da população mais vulnerável.

Diferente do ACS, que realiza a visita domiciliar diariamente, o enfermeiro destina alguns turnos de sua semana para esta atividade. Neste estudo, a média de turnos por semana destinados a visita domiciliar foi de 2,63 , variando de dois a quatro turnos. Os enfermeiros referiram que devido a grande demanda de atividades na UBSF é difícil realizar quatro turnos de visita domiciliar, como foi pactuado pela coordenação local de saúde. Para os ACS o pactuado foi de oito a dez visitas domiciliares por dia, o que totaliza 40 ou 50 por semana.

Além disso, os enfermeiros relatam que há uma exigência para cumprimento de metas estatísticas tanto para a realização da visita domiciliar quanto para as demais atividades da UBSF. Sendo assim, os enfermeiros passam por um dilema, pois, por vezes, precisam optar por realizar um número menor de visitas domiciliares para cumprir com os demais objetivos estatísticos. Semelhante a outro estudo, observou-se que os momentos para realização da visita domiciliar, avaliação e planejamento das atividades são reduzidos devido ao cumprimento de metas, fato que contribui para a prática ser centrada nas demandas imediatas dos usuários ${ }^{(11)}$. Nesse momento questiona-se o foco dos enfermeiros se tem sido a promoção da saúde, pilar da ESF, ou a assistência baseada em riscos e curativa.

Neste contexto, percebe-se a importância do ACS na identificação das necessidades de saúde e na continuidade do cuidado, pois ele é o responsável por detectar as demandas da população e acompanhar a saúde das famílias, o que é preciso ser feito diariamente através da visita domiciliar. Já a visita domiciliar do enfermeiro voltase para a intervenção da demanda, o que, essencialmente, não necessita ser realizada diariamente.

Alguns enfermeiros identificam a necessidade de realizar com maior frequência a visita domiciliar. Para isso, eles consideram essencial uma maior organização das atividades na UBSF, deixando livre os turnos destinados a visita domiciliar.

A visita domiciliar é um espaço que se a gente não brigar por ele, não acontece. Porque nós enfermeiros temos uma carga extremamente grande de atividades, se deixar você só fica dentro da unidade. (E7)

As visitas domiciliares do enfermeiro geralmente são programadas na reunião de equipe que ocorre semanalmente. Nela, é elaborado um cronograma dos próximos domicílios a serem visitados, tendo como base o repasse do ACS das principais necessidades identificadas na área.

Os enfermeiros e os ACS já saem para a visita domiciliar conhecendo a história clínica e social da família, sendo que por vezes eles resgatam essa história no prontuário ou na reunião de equipe. Planejar a visita domiciliar é fundamental, pois possibilita ao profissional organizar e dinamizar seu tempo, uma vez que as tarefas são muitas. O planejamento possibilita conhecer a história familiar previamente, favorecendo a aproximação e a orientação na visita domiciliar. Além de definir os dados que precisam ser levantados junto à família para serem agregados ao projeto terapêutico da família e ao plano de visita $^{(24)}$.

Quanto ao horário de realização das visitas domiciliares elas frequentemente são feitas a partir das $9 \mathrm{~h}$ da manhã, uma vez que os enfermeiros e os ACS relataram que parte da comunidade acorda neste horário, sendo necessário respeitar esse costume. Por vezes, a família é avisada antecipadamente a respeito da visita domiciliar a ser realizada, especialmente em casos nos quais há coleta de sangue e urina, ou curativos. O horário preferencial das famílias para a realização da visita domiciliar é um critério importante a ser considerado para que as visitas não sejam infrutíferas ${ }^{(24)}$.

Em relação ao tempo de duração da visita domiciliar alguns relatos indicam uma grande variabilidade, sendo relativo a cada família e a necessidade apresentada. A necessidade de definir uma duração de tempo para cada visita domiciliar torna-se uma questão limitadora na assistência prestada pelos profissionais, uma vez que eles buscam cumprir com a previsão para não interferir nas outras atividades agendadas, o que pode diminuir a qualidade do trabalho.

Após a realização da visita domiciliar do enfermeiro com o ACS são feitos relatórios e é planejado o andamento do cuidado àquela família, como uma visita domiciliar de retorno do enfermeiro ou o encaminhamento a outro profissional da equipe de saúde. Alguns enfermeiros discutem os casos com os ACS logo após retornar para a UBSF, porém outras preferem deixar a discussão para a reunião de equipe semanal.

Quando o ACS vai sozinho na visita domiciliar ele geralmente volta para a UBSF ao término do turno, faz suas anotações e somente repassa para o enfermeiro situações emergentes, caso contrário, ele aguarda a reunião de equipe. Também foram evidenciadas situações em que a prática de saúde à família é vista meramente 
como um trabalho estatístico, no qual a continuidade do cuidado não é valorizada pelo profissional.

Se for uma família tranquila, passou, foi trabalho, vira estatística. Se for uma visita em que o paciente precisa de mais cuidado será discutido e depois vira estatística. (A3)

Por fim, um aspecto que chamou atenção foi o fato do planejamento ser assistemático. Alguns profissionais afirmam que não existe um planejamento fixo, pois ao chegar até a microárea outras demandas podem surgir e modificar o cronograma já estabelecido. Além disso, os profissionais organizam-se de modo diversificado, não existindo um padrão. Notou-se que é necessário desenvolver um planejamento estratégico, no qual os ajustes e as mudanças do cotidiano não prejudiquem o andamento das atividades, principalmente a realização da visita domiciliar.

\section{CONCLUSÃO}

Dos resultados expostos nesta pesquisa, é relevante enfatizar que o principal limitador dos enfermeiros e agentes comunitários de saúde para a realização das visitas domiciliares é a sobrecarga de trabalho na UBSF. Além disso, foram evidenciadas situações que geram dificuldade para a realização da visita domiciliar. A violência e a dificuldade de acesso a certos pontos da comunidade são dificuldades encontradas tanto pelos enfermeiros quanto pelos ACS.

A visita domiciliar possibilita o fortalecimento do vínculo entre enfermeiro e ACS. Entretanto, a interação entre estes profissionais na visita domiciliar ainda é baixa. Diversas vezes, o ACS está presente na visita domiciliar do enfermeiro apenas como acompanhante. Embora o enfermeiro desenvolva diversas práticas de cuidado na visita domiciliar, percebeu-se que ele tem desenvolvido em maior número as práticas relacionadas à intervenção na saúde. Assim, ele tem deixado de utilizar o espaço da visita domiciliar para promover a saúde, fortalecer o vínculo com as famílias e estimular a interação profissional com o ACS.

Pode-se concluir que a visita domiciliar é considerada importante pelos enfermeiros e ACS. No entanto, é necessário abordar e buscar alternativas para os pontos críticos desta atividade: as dificuldades para sua realização, a pequena interação entre enfermeiro e ACS, e o planejamento assistemático.

Recomenda-se que a coordenação local de saúde da ESF avalie as UBSF quanto as demandas de serviço existentes em cada local e os recursos humanos e estruturais disponíveis, a fim de tornar compatível a demanda com o número de profissionais da equipe. Ainda, seria interessante intensificar os momentos de educação permanente, a fim de discutir de modo problematizador os papéis e as atribuições de cada membro da equipe na visita domiciliar, assim como, a sistematização desta atividade.

Por fim, sugere-se que sejam desenvolvidos mais estudos em torno das práticas de saúde do enfermeiro e do ACS na visita domiciliar da ESF, revelando outros dados, perspectivas e percepções, uma vez que esta temática mostrou-se reveladora. O aprofundamento teórico e prático desta discussão permitirá um maior comprometimento dos profissionais com a visita domiciliar, qualificando ainda mais a proposta da ESF.

os desafios de se mover no território. Interface - Comunic., Saude, Educ. 2013;17(44):61-73.

6. Polaro SHI, Gonçalves LHT, Alvarez AM. Construindo o fazer gerontológico pelas

enfermeiras das Unidades de Estratégia Saúde da Família. Rev Esc Enferm USP. 2013;47(1):160-7.

7. Alonso ILK. Luzes e sombras no ritual do encontro entre o universo profissional e o mundo da intimidade familiar: a intervenção profissional na saúde da família em âmbito domiciliar [thesis]. Florianópolis: Programa de Pós-Graduação em Enfermagem/ Universidade Federal de Santa Catarina; 2003. 8. Instituto Brasileiro de Geografia e Estatística [Internet]. Brasília: Ministério do planejamento, Orçamento e Gestão (BR) [cited 2013 nov 09]. Pesquisa Nacional por Amostra de Domicílios. Síntese de Indicadores 2010. Available from: http://www.ibge.gov.br/home/estatistica/populacao/censo2010/. Acesso em: 09 nov. 2013.

9. Bardin L. Análise de conteúdo. 6a. ed. Lisboa: Edições 70; 2011. 280 p.

10. Conselho Nacional de Saúde, Ministério da Saúde. Resolução No 196/96 - normas regulamentadoras de pesquisas envolvendo seres humanos. Brasília (Brasil): Ministério da Saúde; 1997. 
11. Trad LAB, Menezes e Rocha AAR. Condições e processo de trabalho no cotidiano

do Programa Saúde da Família: coerência com princípios da humanização em saúde. Cienc saude colet. 2011;16(3):19691980.

12. Sakata KN, Mishima SM. Articulação das ações e interação dos Agentes Comunitários de Saúde na equipe de Saúde da Família. Rev Esc Enferm USP. 2012; 46(3):665-72.

13. Colomé ICS, Lima MADS, Davis R. Visão de enfermeiras sobre as articulações das ações de saúde entre profissionais de equipes de saúde da família. Rev Esc Enferm USP.

2008;42(2):256-61.

14. Kebian LVA, Acioli S. Visita domiciliar: espaço de práticas de cuidado do enfermeiro e do agente comunitário de saúde. Rev enferm UERJ. 2011;19(3):403-9.

15. Paim JS. Modelos de atenção à saúde no Brasil. In: Giovanella L, Escorel S, Lobato LVC, Noronha JC, Carvalho AI (orgs.). Políticas e sistema de saúde no Brasil. 2a. Ed. Rio de Janeiro: Ed Fiocruz; 2013. p. 547-73.

16. Sakata KN, Almeida MCP, Alvarenga AM, Craco PF, Pereira MJB. Concepções da equipe de saúde da família sobre as visitas domiciliares. Rev Bras Enferm. 2007;60(6):659-64.

17. Peres CRFB, Junior ALC, Silva RF, Marin MJS. Ser agente comunitário de saúde: motivação e significado. REME - Rev. Min. Enferm. 2010;14(4):559-565.

18. Rosa AJ, Bonfanti AL, Carvalho CS. O sofrimento psíquico de agentes comunitários de saúde e suas relações com o trabalho. Saude soc. $2012 ; 21(1): 141-52$.

19. Pinto ESG, Menezes RMP, Villa TCS. Situação de trabalho dos profissionais da estratégia saúde da família em Ceará-Mirim. Rev Esc Enferm USP. 2010;44(3):657-64.

20. Moura FJM de. O mundo do trabalho da enfermeira no programa saúde da família: riscos e desgastes no enfrentamento da violência estrutural [thesis].Rio de Janeiro: Escola de Enfermagem Anna Nery/Universidade Federal do Rio de Janeiro; 2005.

21. Souza LJR de, Freitas MCS; O agente comunitário de saúde: violência e sofrimento no trabalho a céu aberto. Rev baiana de saúde pública. 2011;35(1):96-109.

22. Dejours C. Subjetividade, trabalho e ação. Rev Produção. 2004; 14(3):27-34.

23. Lancman S, Ghirardi MIG, Castro ED de, Tuacek TA.

Repercussões da violência na saúde mental de trabalhadores do Programa Saúde da Família. Rev saúde pública. 2009;

43(4):682-8.

24. Abrahão AL, Lagrange V. A Visita Domiciliar como uma Estratégia da Assistência no Domicílio. In: Morosini MVGC, Corbo AMDA (org.). Modelos de atenção e a saúde da família. Rio de Janeiro: EPSJV/Fiocruz; 2007. p. 151-171.

Artigo recebido em 21/09/12.

Aprovado para publicação em 23/10/13.

Artigo publicado em 31/03/2014. 